\title{
Especificidades, prioridades y desafíos para el rol de la Matrona, Matrón, en contexto de pandemia por COVID-19
}

\author{
Specificities, Priorities and Challenges for the Role of the Midwifes, \\ in the Context of a COVID-19 Pandemic
}

\author{
Paulina López Orellana ${ }^{1}$ \\ ${ }^{1}$ Matrona, MSc, PhD, Escuela de Obstetricia y Puericultura, Universidad de Valparaíso (hasta el año 2019) \\ Valparaíso, Chile. \\ *Autor para correspondencia: paulina.lopez@uv.cl \\ RECIBIDO: 15 de Julio de 2020 \\ APROBADO: 08 de Septiembre de 2020

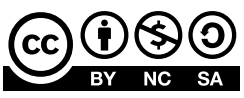

DOI: 10.22370/rev.mat.1.2020.2360

LOS AUTORES DECLARAN NO TENER CONFLICTO DE INTERESES

Palabras claves: SARS-CoV-2, COVID-19; Salud Materna, Cuidado Perinatal, Matronería.

Key words: SARS-CoV-2; COVID-19; Maternal Health; Perinatal Care; Midwifery.

\section{RESUMEN}

La pandemia por virus SARS-CoV-2, de rápida expansión, ha provocado drásticos cambios globales, enfermedades y muertes. Los equipos de salud han enfrentado la urgencia y el control del contagio con nuevas exigencias.

Este trabajo pretende aportar elementos de reflexión para identificar especificidades, prioridades y desafíos relacionados con el quehacer profesional orientado a la protección de la salud de la mujer en el proceso reproductivo y la salud perinatal, en el contexto de pandemia.

Se revisaron publicaciones científicas relacionadas con COVID-19 en los siguientes tópicos : aspectos epidemiológicos, riesgos obstétricos y perinatales, implicancias para el rol profesional, preguntas por investigar y probables futuros escenarios.

El COVID-19 es de alto riesgo materno y perinatal (morbilidad materna, cesárea, parto prematuro); hay transmisión madre-hijo por proximidad, pero la lactancia materna es aconsejable. En contexto de pan- demia, la atención clínica es más compleja y distante por protocolo. Matronas y matrones pueden liderar un modelo de atención a la mujer y familia altamente humanizado desde el inicio del proceso reproductivo. Específicamente, en el nivel primario se debe priorizar la prevención, detectar e investigar el riesgo. En el nivel hospitalario, en tanto, es prioridad la protección del bienestar de la madre y del recién nacido en su más amplio concepto.

\section{ABSTRACT}

The rapidly expanding SARS-CoV-2 virus pandemic has caused drastic global changes, illness and deaths. Health teams have faced the urgency and control of contagion with new demands.

This work aims to communicate elements of reflection to identify specificities, priorities and challenges to the professional role in the protection of women's health in the reproductive process and of perinatal health, in the context of the COVID-19 pandemic. Scientific publications related to COVID-19 
were reviewed on the following topics: epidemiological aspects, obstetric and perinatal risks, implications for the midwifery, questions to be investigated and probable future scenarios.

COVID-19 is related with high maternal and perinatal risk (maternal morbidity, caesarean section and premature delivery), there is mother-to-child transmission by proximity, but breastfeeding is advisable. In the context of a pandemic, clinical care is more complex and more distant by protocol. Midwives can lead a highly humanized model of care for women and families from the beginning of the reproductive process. Specifically, at the primary level they must prioritize prevention, detect and investigate risk. At the hospital level, the protection of the well-being of the mother and the newborn in its broadest concept is a priority.

\section{INTRODUCCIÓN}

El nuevo coronavirus SARS-CoV-2, causante de una pandemia por la enfermedad COVID-19, afecta a casi todas las regiones del mundo y nos pone frente a lo desconocido. Es el último dentro de una larga lista de virus que han contagiado a la especie humana en los últimos 20 años (Nipah, SARS-CoV, MERSCov, ZIKA, Ébola, H7N9, H1N1) (1).

Epidemiológicamente hablando, el virus tiene una elevada capacidad de contagio. Los estudios en China mostraron que basta con introducir tan solo cuatro casos en una localidad para tener alta probabilidad (>50\%) de que la enfermedad se expanda (2).

La enfermedad COVID-19 se considera de letalidad global moderada comparada con sus antecesores SARS y MERS. La letalidad es un indicador heterogéneo y dependiente de la capacidad de un país para identificar los casos y las causas de muerte.

Al respecto, la Organización mundial de la Salud (OMS) recomienda medir la Razón de Letalidad Real o IFR. El valor de este indicador fluctúa entre $0,5 \%$ y $1 \%(3)$.

La mayor probabilidad de morir por COVID-19 se presenta en las formas críticas (15\% de casos), y severas (5\% de casos); aumenta con la edad a partir de 60 años y más aún en presencia de enfermedades crónicas (hipertensión arterial, obesidad, diabetes, enfermedad renal, condiciones de inmunodepresión) (4).

Dado que la mayoría de los casos se concentra en el grupo etario de 20 a 59 años, este grupo representa un gran desafío para la prevención y cuidados.

La pregunta para matronas y matrones es: ¿Cómo impactará esta pandemia, sus rebrotes y otras condiciones que se anuncian al proceso reproductivo del ser humano? ¿Cómo dar respuestas pertinentes y adaptadas, para proteger el complejo y frágil proceso psicoafectivo durante la gestación, el parto y, más temprano, al momento de desear un(a) hijo (a)? ¿Qué necesitamos saber y decir en medio de una marea mediática que alerta, culpabiliza e infunde temor?

El principal objetivo del presente trabajo es identificar y aportar algunos elementos de reflexión y análisis que permitan identificar las especificidades, las prioridades y los desafíos para la profesión de la matrona y el matrón, en favor de la salud de la mujer en proceso reproductivo y de la salud perinatal, en el contexto señalado.

\section{REFLEXIÓN}

En la actualidad, Chile ocupa el lugar 14 a nivel mundial en cuanto a número de personas contagiadas con COVID-19 (5), con una mortalidad acumulada de 77,6 decesos por cada 100.000 habitantes, luego de 180 días desde que fuera diagnosticado el primer caso (6).

Lo que indican estas cifras es que la epidemia tiene diferente impacto según el lugar donde se desarrolla. El mayor o menor estrago depende de las condiciones sanitarias de un país y de su sistema de salud: accesibilidad geográfica, accesibilidad por costo, por cobertura, calidad de la atención, el enfoque de las políticas de estado, presencia o ausencia de campañas preventivas y explicativas por grupos de edades, momento de inicio de las medidas sanitarias respecto al número de fallecidos, tipo de confinamiento. El daño provocado por una epidemia depende de las características demográficas de la población (densidad poblacional, proporción de población mayor de 65 años, urbanismo o ruralidad), de su estilo de vida y de sus factores de riesgo. 
Relacionados con las características socioeconómicas influyen asimismo los niveles de pobreza, el hacinamiento en el hogar, en los lugares de trabajo y en los medios de transportes. Al observar este conjunto de variables, es posible ubicar en qué grupos de la población y en qué lugares se sitúan los más altos riesgos.

Atendiendo a lo expuesto, en América Latina, los países con menos casos y menos muertes por COVID-19 son aquellos que han iniciado precozmente las medidas de contención y limitación de la cadena de contagio mediante: cuarentenas, aislamiento y trazabilidad de casos (Costa Rica, Cuba, Uruguay, Venezuela), realización de test de diagnóstico (Costa Rica), notificaciones y registros de deceso (Costa Rica), campañas masivas (Cuba, Venezuela) y apoyo económico a la población vulnerable (Costa Rica, Uruguay) $(7,8)$. Como resultado, luego de seis meses de pandemia, Cuba (11,3 millones) ha reportado 3.759 casos y 92 decesos, Costa Rica (4,8 millones) ha reportado 24.509 casos y 355 decesos y Uruguay $(3,4$ millones) con 1.543 casos y 43 muertes $(5,9,10)$.

En contraposición, Estados Unidos, Brasil y Chile, países con PIB superior al promedio del continente y con amplios recursos sanitarios, presentaron fallas en uno o más de los aspectos señalados, han presentado largos ciclos de elevado contagio y mortalidad (7).

\section{La pandemia y el pánico}

La pandemia por COVID-19 tiene un breve recorrido a escala global, pero su impacto ha sembrado pánico como ninguna otra y "el pánico viaja más rápido que el virus", vía los medios de comunicación de masas (11).

El artículo "Evidence over hysteria-COVID-19" (Aaron Ginn, 20 marzo 2020) critica el enfoque sensacionalista que distintos medios de comunicación han dado a esta pandemia. Su artículo fue censurado y retirado de la internet. Ello dio cuenta de que es difícil escapar al discurso mediático que se erige como una verdad total, con carácter dominante y censurador. Considerando la calidad de sus fuentes (Universidad de John Hopkins, Institutos de Salud entre otras), el artículo ha tenido defensores en nombre de la libertad de expresión (12).
En salud pública el pánico no es anodino, pues ha conducido a medidas erróneas por parte de algunos gobiernos y a conductas incoherentes de la ciudadanía sin relación con la protección ni con la prevención propiamente tal. Mantenido en el tiempo, afecta la salud mental de la población, especialmente la más vulnerable, y lesiona la confianza en los líderes políticos, en la ciencia y en la misma salud pública $(12,13)$.

En el ámbito de los procesos reproductivos se asume que, durante la gestación, la mujer necesita conectarse con la vida y con el futuro para realizar su proceso de maternidad. Los eventos cotidianamente peligrosos son generadores de estrés crónico en la gestante y representan un riesgo para la salud materna y perinatal. Los estudios en China han mostrado que las mujeres aumentan significativamente el score de depresión y ansiedad (medido por Escala de Edimburgo) en contexto de pandemia sanitaria y distinguen claramente el rol de los noticieros y reportajes centrados en el recuento de enfermos y de muerte. Los autores señalan que una pandemia por enfermedad infecciosa puede representar para la embarazada una amenaza mayor que la de una catástrofe natural (14).

Quizás porque el factor de amenaza permanece durante un largo período de tiempo, un agente infeccioso altamente contagioso puede estar en todo lugar sin ser visible, puede ingresar al organismo y provocar daño a la madre y a su hijo(a) pudiendo llegar a causar la muerte.

\section{COVID-19 en la gestación}

El análisis de varias series de casos de COVID-19 en gestantes coinciden en que su probabilidad de contagio es la misma que la de la población general. En una de las más amplias series $(\mathrm{n}=757)$, la incidencia fue del 12,2\% (15). La mayoría cursa la enfermedad con forma asintomática o leve.

Con sintomatología presente, se describe con mayor frecuencia tos y fiebre. Para prevenir el contagio intrahospitalario algunos autores recomiendan el test específico de RT-PCR al ingreso al preparto, lo que permite detectar las formas asintomáticas y proteger al feto, al recién nacido y al equipo de salud (16). 
En presencia de un test positivo, el embarazo, el parto y el recién nacido se consideran de alto riesgo. Es esperable mayor frecuencia de rotura prematura de membranas, de fiebre intraparto, sangrado placentario y la posibilidad de descompensación respiratoria. Es también más probable la interrupción del embarazo por operación cesárea para aliviar el distrés respiratorio materno o fetal.

\section{Mortalidad materna}

La forma severa es de rara frecuencia y la neumonía es de forma leve con buena respuesta al tratamiento. Dado que la población materna es joven, la muerte por COVID-19 podría considerarse un evento raro, pero no todo está escrito. Falta tiempo y estudios concluyentes para establecer la mortalidad en grupos específicos (15).

Los autores de un estudio de siete casos de muerte materna por COVID-19 en Irán, alertan que la gestante puede ser la más vulnerable del grupo familiar cuando hay contaminación en el hogar, allí la velocidad de contagio es muy alta y entonces las medidas de aislamiento y la consulta hospitalaria debe ser precoz (17).

Velar por la salud y bienestar de la diada madrehijo(a).

Lo primero es asumir que las mujeres gestantes -frente a cualquier pandemia- requieren un sistema particular y adaptado de prevención, diagnóstico y tratamiento. Matronas y matrones deben aportar desde donde trabajen para que eso se cumpla mediante participación directa en la elaboración de protocolos, normas y guías y si esto no es posible, en su validación y necesaria evaluación.

En obstetricia y perinatología se sabe que no todos los virus son igualmente dañinos. Difieren respecto del momento en que actúan durante la gestación, difieren respecto del daño fetal y perinatal, respecto de la expresión clínica y sus secuelas.

Con el SARS-CoV-2, no hay series de casos que lo sitúen como virus de alta gravedad en obstetricia. No se puede igualar a este virus con el SARS-CoV, por el cual el 50\% de las embarazadas infectadas ingresó a la unidad de cuidados intensivos (UCI) y provocó una altísima mortalidad materna (25\%) ni con la gri- pe H1N1 en el año 2009 donde las embarazadas representaban el $1 \%$ de los casos y el $5 \%$ de las muertes (18).

Hasta el momento, la transmisión vertical por SARS-CoV-2 no ha podido ser probada. La hipótesis de que existiría transmisión vertical se formula a partir de la presencia de IgG y de IgM y presencia de citoquinas en la sangre de los recién nacidos, sin embargo, al examen de RT-PCR no se ha encontrado material genético del virus ni en sangre del cordón, ni en el líquido amniótico ni en la leche materna (19).

A nivel perinatal, el mayor riesgo es el nacimiento prematuro medicamente indicado. El estado de los recién nacidos de término es óptimo en la gran mayoría de las series observadas. En los prematuros la evolución está ligada a la edad gestacional (20-22).

La contaminación madre-recién nacido es posible por contacto cercano. Aunque la mayoría de las formas neonatales son asintomáticas, las formas severas son posibles y frecuentes en el grupo de lactantes menores de 6 meses (23).

La lactancia materna sigue siendo indicada con aplicación de las medidas preventivas señaladas por los protocolos (FIGO, OMS y sociedades de expertos). Es altamente recomendada en caso de nacimiento prematuro. Hay que agregar que en partos y nacimientos muy medicalizados debido a la enfermedad, al riesgo y por la urgencia, la lactancia materna es un espacio privilegiado para la protección integral del bienestar de la diada madre-hija(o) en aislamiento.

Frente a un gran conjunto de riesgos maternos y perinatales, la pregunta es ¿cuándo actuar y cómo actuar? Evidentemente los recursos de atención son limitados, pero las matronas y matrones trabajamos con un set de herramientas de prevención y protección que no tiene costo material. Es el vínculo de confianza, la comunicación, el acompañamiento, el apoyo.

En contexto de pandemia todas las formas de humanización de la atención se vuelven necesarias cualquiera sea el nivel de atención (24). Un objetivo de trabajo es lograr que la mujer disminuya el nivel de temor, que demuestre confianza para comunicar lo que le ocurre. Llegado a ese punto, el rol profesional se despliega naturalmente. 
En el nivel hospitalario hace falta una declaración de apoyo formal y serenamente comunicada a la mujer y también al padre. Ellos deben saber que la matrona o el matrón está presente y disponible. En este caso la atención clínica no es suficiente. En el nivel primario de atención es posible establecer el diálogo, abordar miedos y creencias que las mujeres, sus pareja y familia han cultivado en el medio social, aclarar conceptos de la pandemia, entregar información y consejos prácticos. Conocer las condiciones de vida familiar y la rutina permite hacer prevención caso a caso. Esa es la prevención más efectiva.

Es importante entregar a cada mujer una cartilla para su protección y la del feto y recién nacido, sin mensajes alarmantes, mensajes que le entreguen confianza, que le otorguen autonomía para actuar.

Las medidas de contención deben ser adaptadas a las gestantes y puérperas, ellas tienen necesidades particulares y hay que reconocerlas en la práctica. Por ejemplo, durante el confinamiento la necesidad de ejercicio físico puede resolverse con un salvoconducto que las autorice a salir al parque a algún área verde con una persona acompañante. Una indicación que involucre la voluntad de la familia o de la pareja debe ser dada por escrito, por ejemplo: reducir el nivel de exposición a factores frecuentemente estresores en el hogar (televisión, ruido, discusiones banales) y favorecer instancias simples de distracción. Una mención especial merece la detección de situaciones de alto riesgo o de vulneración de derechos (ej.: violencia doméstica, ambientes laborales hostiles, no cumplimiento en el hogar de las medidas de prevención o de aislamiento) que obligan a resolver con un rol profesional activo y no solo de consejería.

A nivel de la prevención secundaria las mejores acciones son las que se adaptan a los perfiles de riesgo. La evidencia acumulada hasta aquí, reconoce algunas condiciones que hacen a las personas más vulnerables frente a la COVID-19. La Tabla 1 muestra, a modo de orientación para focalizar acciones de prevención, algunas características que han estado mayormente presentes en las formas clínicas severas de COVID-19.
Tabla. 1. Condiciones de la población general y de mujeres gestantes que han sido mayormente descritas en formas severas de COVID-19.

\section{Características}

\begin{tabular}{cc} 
Población General & Gestantes \\
\hline Mayor de 70 años & $\begin{array}{c}\text { Gestantes tardías } \\
\text { (mayor de 35 años) }\end{array}$ \\
\hline $\begin{array}{c}\text { Mayor de 70 años con } \\
\text { morbilidades crónicas. }\end{array}$ & $\begin{array}{c}\text { Gestante tardía con } \\
\text { comorbilidades. }\end{array}$ \\
\hline Morbilidades crónicas ${ }^{1}$ \\
\hline Déficit de respuesta inmunitaria \\
\hline Tratamientos inmunosupresores \\
\hline \multicolumn{3}{c}{ Anemia } \\
\hline CIH & Bajo Peso \\
\hline Cáncer & Estrés crónico \\
\hline & Depresión \\
\hline
\end{tabular}

Alta vulnerabilidad psicosocial: uso de drogas, extrema pobreza, confinamiento.

Eventos de vida que producen baja en la respuesta inmunitaria ejemplo: separación reciente, agotamiento físico y psíquico.

${ }^{1}$ Obesidad, Diabetes, Hipertensión arterial, Falla renal, enfermedad cardiovascular. Fuente: elaboración propia basada en revisión de artículos científicos publicados a julio 2020.

\section{El estado de la investigación en el área de la ma- trona o el matrón}

La corta historia de la pandemia no ha logrado cubrir la duración de una gestación hasta las 42 semanas. Ello impide extraer conclusiones definitivas. La cautela debe imponerse. Hay vacíos importantes por resolver, por ejemplo ¿cuál es la respuesta materna y fetal durante el primer trimestre? Para observar todo el periodo de gestación se requieren estudios de cohorte, hay algunos en curso, pero sus resultados no están aún disponibles (18). Faltan series comparativas. Hasta el momento, la investigación se sitúa en el nivel descriptivo.

Matronas y matrones entregan diariamente atención a grandes grupos de la población femenina esto les da la posibilidad de realizar investigación clínica por observación y seguimiento. Formular estudios 
de investigación-acción para sistematizar estrategias de prevención y de afrontamiento validadas por la misma comunidad. Pueden participar en estudios epidemiológicos analíticos enfocado a identificar y medir el rol de los factores de riesgo sociodemográficos, socioeconómicos, laborales y otros relacionados con los niveles de exposición de las poblaciones más vulnerables, que son, a su vez las más pobres.

\section{CONCLUSIÓN}

Para una enfermedad emergente como la COVID-19 las evidencias son aún parciales pero suficientes para identificar algunos factores asociados a su gravedad. Además, permiten conocer resultados maternos y perinatales que forman parte del impacto específico que tiene el SARS-CoV-2 en el proceso de gestación, parto y nacimiento.

Con ello, es posible identificar la necesidad de aumentar las instancias de humanización de la atención, de la prevención y protección de la mujer gestante, del feto y del recién nacido.

Una visión estratégica que deberá intervenir en esta u otras pandemias similares y que forma parte del rol profesional de la matrona, matrón, como integrante del equipo de salud.

\section{REFERENCIAS}

1. Dhama K, Khan S, Tiwari R, Sircar S, Bhat S, Malik YS, et al. Coronavirus Disease 2019-COVID-19. Clin. Microbiol. Rev. 2020;33(4):1-48.

2. Kucharski AJ, Russell TW, Diamond C, Liu Y, Edmunds J, Funk S, et al. Early dynamics of transmission and control of COVID-19: a mathematical modelling study. Lancet Infect Dis.2020;20(5):553-8.

3. Organización Mundial de la Salud. Estimación de la mortalidad de la COVID-19: nota científica, 4 de agosto de 2020 [Internet]. Ginebra: OMS; 2020. Reporte No.: WHO/2019-nCoV/Sci_Brief/Mortality/2020.1 Disponible en: https://apps.who.int/iris/ handle/10665/333857

4. De Greef Jea. COVID-19: infection par le virus SARS-CoV-2. Louvain Med 2020. 2020;136(0506):290-301.
5. Johns Hopkins University. Corona Virus Resource Center [Internet]. 2020 [actualizado 8/27/2020; citado 25/08/2020]. Disponible en: https://coronavirus.jhu.edu/region

6. Chile, Ministerio de Salud. Informe Epidemiológico No 45. Enfermedad por SARS-CoV-2 (COVID-19). Santiago de Chile: MINSAL; 2020. Disponible en: https://www.minsal.cl/wp-content/ uploads/2020/08/Informe-Epidemiologico-45-MINSAL.pdf

7. Ruiz-Caro A. Contrastes entre las estrategias para derrotar al COVID-19 en Sudamérica [Internet]. Americas Program; 2020 [actualizado 02/07/2020; citado 8/23/2020]. Disponible en: https://www. americas.org/es/contrastes-entre-las-estrategiaspara-derrotar-al-covid-19-en-sudamerica/

8. Coronavirus en Cuba: cómo funciona el agresivo modelo de vigilancia epidemiológica contra el Covid-19 [press release]. El Mostrador [Internet]; 2020 [actualizado 03/05/2020; citado 23/08/2020]. Disponible en https://www.elmostrador.cl/dia/2020/05/03/coronavirus-en-cubacomo-funciona-el-agresivo-modelo-de-vigilanciaepidemiologica-contra-la-covid-19/

9. Pan American Health Organization, World Health Organization. COVID-19 Americas' Regional Dashboard. Geographic Distribution of Cases and Deaths Updated [Internet]. Geneva: PAHO-WHO; 2020 [actualizado 8/23/2020; citedo 23/08/2020]. Disponible en: https://who.maps.arcgis.com/apps/ dashboards/efb745c3d88647779beccb91c0e715f9

10. Pan American Health Organization. COVID-19 data reported by countries and territories in the Region of the Americas [Internet]. Washington: PAHO; 2020 [actualizado 23/08/2020; citado 23/08/2020]. Disponible en: https://ais.paho.org/ phip/viz/COVID-19EpiDashboard.asp

11. Depoux A, Martin S, Karafillakis E, Preet R, Wilder-Smith A, Larson $\mathrm{H}$. The pandemic of social media panic travels faster than the COVID-19 outbreak. J. Travel Med. 2020;27(3).

12. Dornan C. Science Disinformation in a Time of Pandemic [Internet]. Public Policy Forum; 2020 [actualizado 11/06/2020; citado 25/08/2020]. Disponible en: https://ppforum.ca/publications/science-disinformation-in-a-time-of-pandemic/

13. Ioannidis JPA. Coronavirus disease 2019: The harms of exaggerated information and nonevidence-based measures. Eur J Clin Invest. 2020;50(4):e13222. 
14. Wu Y, Zhang C, Liu H, Duan C, Li C, Fan J, et al. Perinatal depressive and anxiety symptoms of pregnant women along with COVID-19 outbreak in China. Am J Obstet Gynecol. 2020; 223(2): 240.e1240.e9.

15. Fox NS, Melka S. COVID-19 in Pregnant Women: Case Series from One Large New York City Obstetrical Practice. Am J Perinatol. 2020; 37(10):10021004.

16. Mehan A, Venkatesh A, Girish M. COVID-19 in pregnancy: Risk of adverse neonatal outcomes. J Med Virol. 2020;1-3.

17. Hantoushzadeh S, Shamshirsaz AA, Aleyasin A, Seferovic MD, Aski SK, Arian SE, et al. Maternal death due to COVID-19. Am J Obstet Gynecol. 2020; 223(1): 109.e1-109.e16.

18. Peyronnet V, Sibiude J, Deruelle P, Huissoud $\mathrm{C}$, Lescure X, Lucet JC, et al. SARS-CoV-2 infection during pregnancy. Information and proposal of management care. CNGOF. Gynecol Obstet Fertil Senologie. 2020;48(5):436-43.

19. Kimberlin DW, Stagno S. Can SARS-CoV-2 Infection Be Acquired In Utero?: More Definitive Evidence Is Needed. JAMA. 2020;323(18):1788-1789.

20. Kayem G, Alessandrini V, Azria E, Blanc J, Bohec C, Bornes M, et al. A snapshot of the Covid-19 pandemic among pregnant women in France. Journal of gynecology obstetrics and human reproduction. 2020; https://doi.org/10.1016/j.jogoh.2020.101826 [in press].

21. Lokken EM, Walker CL, Delaney S, Kachikis A, Kretzer NM, Erickson A, et al. Clinical Characteristics of 46 Pregnant Women with a SARS-CoV-2 Infection in Washington State. Am J Obstet Gynecol. 2020; S0002-9378(20):30558-5 [Advance online publication].

22. Liu D, Li L, Wu X, Zheng D, Wang J, Yang L, et al. Pregnancy and Perinatal Outcomes of Women With Coronavirus Disease (COVID-19) Pneumonia: A Preliminary Analysis. American Journal of Roentgenology. 2020;215(1):127-32.

23. Parri N, Magistà AM, Marchetti F, Cantoni B, Arrighini A, Romanengo M, et al. Characteristic of COVID-19 infection in pediatric patients: early findings from two Italian Pediatric Research Networks. European journal of pediatrics. 2020; 179:1315-1323.

24. Allande Cussó R, Navarro Navarro C, Porcel Gálvez AM. El cuidado humanizado en la muerte por COVID-19: a propósito de un caso. Enfermería Clínica. 2020. Enferm Clin. 2020; S1130-8621(20)30315-6. 